\title{
complications related to posterior hypospadias Repair
}

\author{
Professor Abdulrahman Sulaiman*, Thayer M. A. Aboush ${ }^{\star *}$, Ahmad Mothar Hamodat**

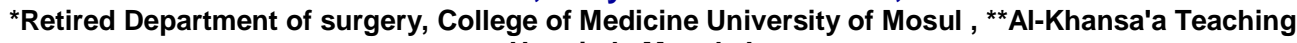 \\ Hospital , Mosul . Iraq \\ Correspondence: abdulrahmanasu@uomosul.edu.iq
}

(Ann Coll Med Mosul 2020; 42 (2):184-189).

Received: $14^{\text {th }}$ Nove. 2020; Accepted: $29^{\text {th }}$ Dece. 2020.

\begin{abstract}
Background: Proximal hypospadias repair carries high complications rates. Stage repair is the standard practice for management but sometimes we may try to do it as a single stage although it is not easy to perform for posterior hypospadias and here appears the need for staged surgery. In this study we assess the out coms and complications of the most commonly used techniques in Mosul pediatric surgery center at alkhansaa teaching hospital .

Objective: To assess the results of management of posterior hypospadias by Tubularized incised plate as single stage and staged repair and to knew the most important complications associated with these two procedures.

Methods: this is prospective study for forty patients who were admitted to Mosul pediatric surgery center at alkhansaa teaching hospital from October 2011 till October 2013, their age ranged from 9 month to 15 years, five of them were operated before with complete failure, 31 patient operated by single stage Tubularized Incised Plate technique and the other 9 by two stage technique and they were followed for 6-18 months.

Results: The total complications rate was (52\%) as follow: (7) cases (17.5\%) develop meatal stenosis, (4) patients $(10 \%)$ develop retrusive meatus, No one develops stricture, (10) cases $(25 \%)$ develop fistula and none of them develop diverticulum, the total complication rate for Single stage TIP technique was (48.3\%) the total complication rate of complications for staged surgery was (66.6\%).

Conclusion: we found that there is no much difference regarding the operative complications rate and the selection of the procedure depend on the individual case, surgeon experience and hospital facilities.
\end{abstract}

KeyWords: posterior hypospadias, proximal hypospadias, TIP, single stage repair, two stages repair.

$$
\begin{aligned}
& \text { المضاعفات المصاحبة لإصلاح المبال التحتاني (النوع الخلفي) }
\end{aligned}
$$

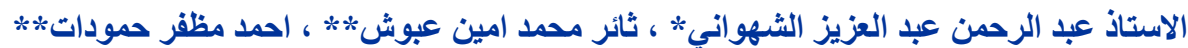

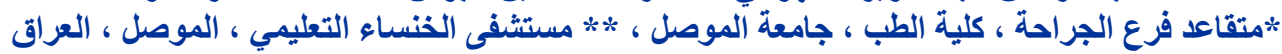

الخلفية : اصلاح المبال التحتاني (النوع الخلفي) يحتمل الكثير من المضاعفات. اجر اء الاصلاح بمرحلة واحدة هو المفضل. لكن

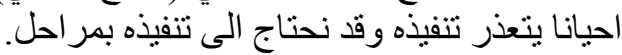
في هذه الدراسة قمنا بتقييم النتائج واهم الثناه المضاعفات المصاحبة لعلاج هذا النوع من المبال التحتاني في مركز جراحة الاطفال

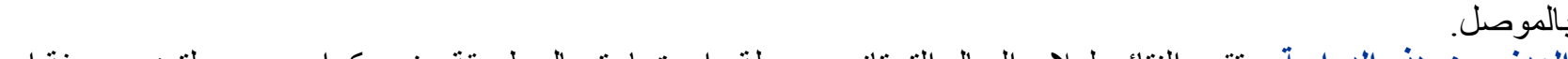
الهـاف من هذه الدراسة : تقييم النتائج لعلاج المبال التحتاني بمرحلة واحدة باستعمال طريقة سنودوكر اس وبمرحلتين ومعرفة اهم

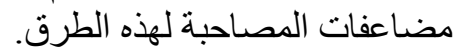

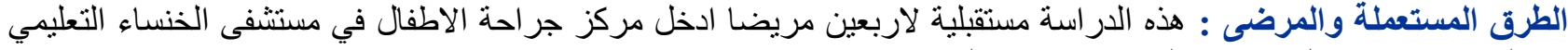

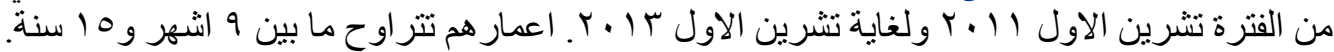

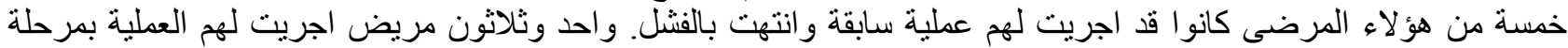

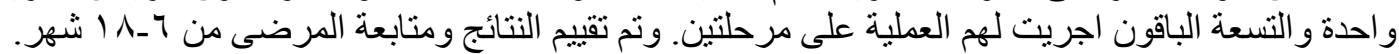

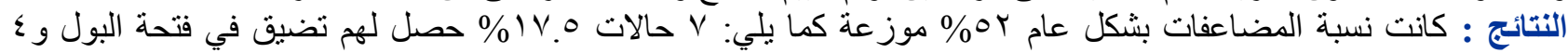

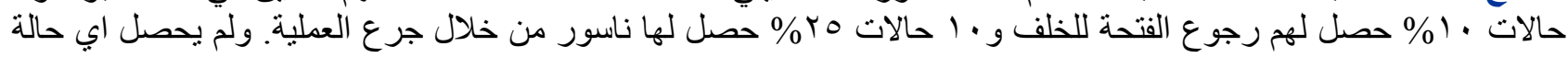


ضيق بالمجرى البولي. ولم تحصل اي حالة جيب او انتفاخ جانبي وقد كانت نسبة المضاعفات في مجموعة المرحلة الواحدة

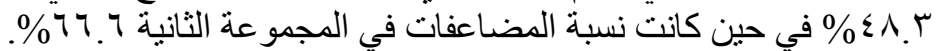

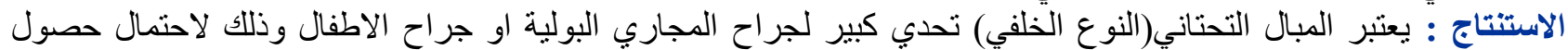

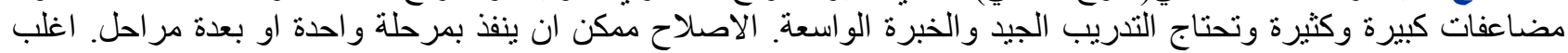

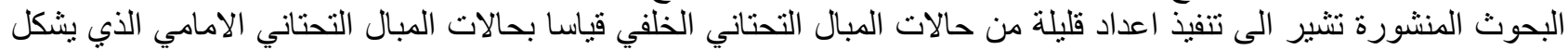

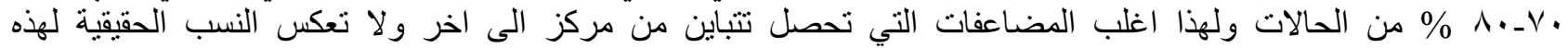
المضاعفات.

الكلمات المفتاحية : مبال تحتاني ، مبال تحتاني خلفي ، عملية مرحلة واحدة ، عمليات متعددة.

\section{INTRODUCTION}

roximal hypospadias represents a major challenge to pediatric surgeons, it carries high complications rate, many procedures and techniques were used to deal with this anomaly. Some of these techniques is one stage ${ }^{2}$ and other procedures are multistage repair, each of these procedures has its own advantages and disadvantages ${ }^{3}$.

The complications rates are considerably high in comparison to the distal type hypospadias ${ }^{4}$. Redo surgery is indicated in some of these complications

In this review (study) we assess the outcome and complications of the most commonly used technique in our pediatric surgery center at alkhansaa teaching hospital in Mosul.

\section{PATIENTS AND METHOD}

This is a prospective study over two years, from October 2011 till October 2013, This study was carried out to report the outcome and complications after repair of proximal hypospadias, The study included forty patients with proximal hypospadias They were admitted to Mosul pediatric surgery center at Al-khansa'a teaching hospital with their age ranged from nine months to fifteen years, classic TIP (Tubularized incised plate) repair done For thirty one patient(26) case with dartos flap and vascularized posterior subcutanous tissue(Dartos tunica) and (5) cases with tunica vaginalis barrier flap. and two stage repair was done for the remaining nine patient Patients are followed up for six to eighteen months at least with estimation of the total complication percentage, complications related to specific procedure ( single or staged procedure).

Inclusion criteria: Patients with proximal (posterior) hypospadias were scheduled to undergo elective repair by single stage (TIP) technique or by two staged procedure (after correction of the cordee and replacement of the uretheral plate with skin graft or flap).
Exclusion criteria include: Anterior and middle types, cases operated by other procedure than we used.

Surgery performed under general anesthesia with tourniquet using catheter from 6 to $10 \mathrm{f}$ according to the age of the child,either by single stage TIP technique (snodograss) or two stage repair.

\section{RESULTS}

Patients' age at the time of surgery ranged from 9 months to 15 years, 32 of them were operated before school age and 8 of them were school age (20\%).

Of our 40 cases the type of hypospadias was (21) with proximal penile shaft, (17) with penoscrotal, (1) with scrotal and (1) with perineal type as shown in Table (1)

Table (1) type of hypospadias

\begin{tabular}{|c|c|c|}
\hline Type & No. & $\%$ \\
\hline $\begin{array}{c}\text { Proximal penile } \\
\text { shaft }\end{array}$ & 21 & 52.5 \\
\hline Penoscrotal & 17 & 42.5 \\
\hline Scrotal & 1 & 2.5 \\
\hline Perineal & 1 & 2.5 \\
\hline Total & 40 & 100 \\
\hline
\end{tabular}

Of those 40 cases 13 was circumcised either outside hospital or by previous operation in cases of redo cases and 27 of cases were not circumcised, the complications rate nearly similar in both groups.

In our study 16 case had simple torsion (less than 30 degree), two patients with significant torsion (more than 90 degree) and 22 without torsion

Chordee was present in 23 patients (57.5\%) and only two $(5 \%)$ of them need dorsal plication 
The type of operation was chosen according to the presence of urethral plate especially after correction of chordee, so two types of operation were selected as in the following table (2)

a) TIP urethroplasty (31) case.

b) Two stage operation (9) cases .(the first stage correction of cordee and replacement of the uretheral palate with skin graft or flap and the second stage is classical TIP technique

Table (2) type of operation

\begin{tabular}{|c|c|c|}
\hline $\begin{array}{c}\text { Type of } \\
\text { operation }\end{array}$ & No. & $\%$ \\
\hline TIP & 31 & 77.5 \\
\hline $\begin{array}{c}\text { Two stage } \\
\text { operation }\end{array}$ & 9 & 22.5 \\
\hline total & 40 & 100 \\
\hline
\end{tabular}

According to our hospital protocol to ensure better medical care ,the average hospital stay for single stage repair was (7) days while in those with two stage most of them admitted for at least 10 days.

Total complications after six months of follow up were $(52 \%)$ as follow : (7) case (17.5\%) develops meatal stenosis that's needs urethral dilatation under general anesthesia , (4) patient (10\%) develops retrusive meatus (2) of them simple and did not need intervention while the other (2) needs surgery (MAGPI) after 6 months, No one develops stricture , (10) case (25\%) develops fistula four of them closed with conservative measures and after dilitation under general anesthesia to ensure distal patency and no one develop cordee.

while (6) of them required operation for closure of fistula six months later, no diverticulum was recorded in our study during our follow up period which may be not enough for such complication to appear ,as shown in table (3)

Table (3) complications after repair

\begin{tabular}{|c|c|c|}
\hline $\begin{array}{c}\text { Type of } \\
\text { complication }\end{array}$ & No. & $\%$ \\
\hline Stenosis & 7 & 17.5 \\
\hline Retrusive meatus & 4 & 10 \\
\hline Stricture & 0 & 0 \\
\hline Fistula & 10 & 25 \\
\hline Diverticulum & 0 & 0 \\
\hline Chordae & 0 & 0 \\
\hline Total & 21 & 52.5 \\
\hline
\end{tabular}

Two main surgical procedures were used in our study, Thirty one $(77.5 \%)$ case were operated by TIP technique as single stage and the total complications rate was $(48.3 \%)$ : five of them $(16.1 \%)$ develops meatal stenosis and all of them did well after urethral dilitation under general anesthesia , three $(9.6 \%)$ cases develops retrusive meatus (1) of them simple while the other two required operation (MAGPI), seven cases (22.5\%) develops fistula four of them needs surgery for closure while the other (3) closed after period on conservative measures and dilatation, and diverticulum and cordee were not reported . in five of our cases with healthy uretheral plate (all of them redo) we used a tunica vaginalis as a second layer flap and only one of them develop fistula which closed after dilatation.

Nine cases $(22.5 \%)$ were operated by 2 stage and the total rate of complications were $(66.6 \%)$. Of those (9) cases: two cases (22.2\%) develops meatal stenosis that responds to urethral calibration, one case $(11.1 \%)$ develops retrusive meatus that required nothing, non develops stricture, three cases (33.3\%) develops fistula all of them required surgery after six months for closure and no diverticulum or cordee during our follow up as shown in table (4).

Table (4) complication related to type of surgery

\begin{tabular}{|c|c|c|c|c|}
\hline $\begin{array}{c}\text { Type of } \\
\text { complication }\end{array}$ & \multicolumn{2}{|c|}{ TIP = 31 } & \multicolumn{2}{c|}{$\begin{array}{c}\text { Staged } \\
\text { technique = 9 }\end{array}$} \\
\cline { 2 - 5 } & No. & $\%$ & No. & $\%$ \\
\hline $\begin{array}{c}\text { Stenosis } \\
\text { Retrusive } \\
\text { meatus }\end{array}$ & 5 & 16.1 & 2 & 22.2 \\
\hline Stricture & - & - & - & - \\
\hline Fistula & 7 & 22.5 & 3 & 33.3 \\
\hline Diverticulum & - & - & - & - \\
\hline chordae & - & - & - & - \\
\hline Total & 15 & 48.3 & 6 & 66.6 \\
\hline
\end{tabular}

\section{DISCUSSION}

Surgical repair of hypospadias has remained one of the most tasking problems for reconstructive surgeons, urologists and pediatric surgeons because of high complication rate ${ }^{6}$.

The fact that there are about 250 different operations to manage this tricky problem indicating that there is no single operation which is favorable by all surgeons of the world because no single technique provides uniformly good results ${ }^{7}$.

One stage repair is naturally favored as it decreases operative trauma, allows use of virgin, unscarred skin, decreases number of hospitalization and thus in turn is economical, but some surgeons remain unhappy with limitations and drawbacks of one stage repair and continue to practice two stage repairs ${ }^{8,9}$. 
Two-stage repair for proximal hypospadias continue to be used despite allegations by some that they represent a "step backwards ${ }^{10,11}$.

A review of the recent literatures suggested that two stage repairs achieve excellent cosmetic and functional results ${ }^{12,13}$.

Our patients had varying degrees of proximal hypospadias (21) with proximal penile shaft, (17) with penoscrotal, (1) with scrotal and (1) with perineal type as in table (1) These figures go with the results of many other series including Sauvage ${ }^{14}$ and Borer ${ }^{15}$.

Chordee was present in 23 patients $(57.5 \%)$. Sixteen (40\%) are mild and 5 (12.5\%) are moderate and $2(5 \%)$ with sever chordee, Most cases of penile curvature are corrected by degloving of the penile skin and only two of them needs dorsal plication for correction of chordee and this is similar to what was found by Sulaiman ${ }^{16}$ who had eight cases $(6.4 \%)$ with chordee all of them corrected by degloving of the penile skin and only one needs dorsal plication . also, similar results were found by Hatem ${ }^{17}$ and singh ${ }^{18}$ who found that $5.7 \%$ of their patients required tunica albuginea plication for correction of chordee. and this is similar to what we found.

Most of our cases were operated by single stage TIP urethroplasty thirty-one $(77.5 \%)$ case. Of those, (26) cases we used lateral based flap and vascularized posterior subcutaneous tissue and in five cases we used tunica vaginalis barrier flap after correction of chordee without transection of the native urethral plate. While the other nine cases $(22.5 \%)$ were operated by two stage procedure as shown in table (2). Khalid ${ }^{19}$ had found similar results in his study who had 25 cases, thirteen $(52 \%)$ of them underwent one stage TIP repair, while two-stage repair was done in 12 patients (48\%)

Badawy and Fahmy ${ }^{20}$ report that the complication rate for the single-stage repair of proximal penile hypospadias is varying from 8$61.5 \%$. This wide variation depends on the surgeon's skill, workload and experience. In multistage repair they found that the incidence of complications rate was $15-70 \%$. In our study the total complication rate was $52 \%$ regardless the surgery weather single or staged surgery.

Snodgrass and Lorenzo ${ }^{21}$ reviewed the records of 33 consecutive patients with a mid-shaft to penoscrotal hypospadias undergoing single stage TIP repair In their study the total number of longterm complications was noted in 11patient (33\%) the most common problem was fistula which occurs in seven boys (21\%).our results is slightly higher than that of Snodgrass and Lorenzo and this may be due to that our cases all are of proximal type while in their study they include mid- shaft type. Among their cases one developed meatal stenosis and need meatotomy while all of our cases improved after dilatation, and they didn't have retrusive meatus while we have one case indicate that we leave bigger meatus than what they did.

Aboulhassan et al ${ }^{22}$ had found in their study in single stage TIP group that they had a total incidence of complications $21 \%$. Meatal stenosis and fistula were the most frequent complications ( $8 \%$ each) and only one case of complete disruption, when we compare with this study we have slightly higher complication rate than what they had.

Snodgrass et al. ${ }^{23}$ in study that involved 36 children, 13 with proximal penile hypospadias, 11 with penoscrotal, nine with scrotal and three with perineal hypospadias, they used a single stage TIP repair in 26 and two stages in 10 children. The authors reported a $13 \%$ complication rate, in the form of one case of urethral stricture and one glanular dehiscence, with an overall success rate of $87 \%$. The follow up was 12 months in 24 children. They showed an improvement in the results with accumulating experience in posterior hypospadias, by using a double-layer closure of the urethral plate and by using the tunica vaginalis as the second layer. This report is similar to what we had found in our five cases when we used a tunica vaginalis as second layer .

Sujijantararat and Chaiyaprasithi ${ }^{24}$ reports complication rate for proximal hypospadias for single stage and it was (37.5\%), it seems lower than our complications rate

Sulaiman ${ }^{16}$ had $60 \%$ overall complication rate in single stage TIP, in previous study done in our center for hypospadias involving all types of hypospadias and most of them of anterior variant, we can see an improvement by decreasing complications rate from $60 \%$ to $(48.3 \%)$.

AlEkrashy et.al ${ }^{25}$ in their study which involve 20 patient they found that the total number of acute complications was six cases $(30 \%)$.urethrocutaneous fistula was the commonest complication, three cases, (15\%) one of the cases has been improved and completely relieved by frequent urethral dilatation and the total number of chronic complications was six patients $(30 \%)$ and the commonest complication was meatal stenosis $(15 \%)$, three cases, one of them needed meatetomy. These results are slightly lower than ours in total complications but we have fewer cases with meatal stenosis. Possibly because we leave wide meatuses.

Nine cases were operated by two stage and the total rate of complications was $(66.6 \%)$ of those cases: two cases $(22.2 \%)$ of them develops meatal stenosis that responds to urethral calibration, (1) 
cases (11.1\%) develops retrusive meatus that required nothing, no stricture was reported, (3) cases (33.3\%) develops fistula all of them required surgery after six months for closure and no diverticulum identified during our follow up period which may be not enough for such complication to appear, as shown in table (4).

Saafan ${ }^{17}$ in study that involve 33 case with proximal hypospadias all of them were operated by 2 stage procedure had found that total complications rate was $27.3 \%$, fistula (24.2\%) and stenosis $(3 \%)$ and no retrusive meatus or diverticulum. His results are lower than ours, and this may be due to that we did 2 stage procedure for small number (only 9 boys) .The incidence of fistula formation is reported to be from $3 \%$ to $50 \%$ and it is higher in proximal hypospadias ${ }^{26}$, which support our results.

Gershbaum et al. ${ }^{27}$ operate 11 children with proximal hypospadias by two stage and a follow-up of 6-18 months. There were complications in only two children (18\%) one with fistula and the other developed urethral diverticulum while in our study with tow stage repair the fistula was $33.3 \%$ and no diverticulum.

Arshad ${ }^{28}$ reported the largest series, including 100 children, in whom Byar's preputial flaps were used. Eighteen children had complications (18\%), in form of a fistula.

Cheng et al. ${ }^{29}$ transected the urethral plate proximally, Preserving the distal portion, and used Byar's flaps to bridge the gap to the native urethra. The authors operated on 14 children and he followed them for 6-36 months. Two children $(14.2 \%)$ had complications, one with a fistula and diverticulum, and the other one with a diverticulum .

Aseem et al. operated on 10 children, with a mean follow-up of 41.5 months, and seven patients (70\%) had complications, all with a fistula, three with meatal stenosis and one with a urethral diverticulum ${ }^{30}$.

Badawy and Fahmy ${ }^{20}$ concluded in their study that: It is clear in these studies that the complication rate is very variable from $14 \%$ to $70 \%$. Complications are not major if they are in the form of a fistula, meatal stenosis and diverticulum, and thus no major complications (e.g. complete dehiscence) were reported in these studies. This support the results which we had found in our 9 cases that operated by 2 stage procedure, our total complications rate was $(66.6 \%)$ which is nearly similar to Aseem et al. ${ }^{30}$

\section{CONCLUSION}

we found that there is no much difference regarding the operative complications rate and the selection of the procedure depend on the individual case, surgeon experience and hospital facilities. Most of the published papers has low number of cases which may not reflect the exact incidence of complications

\section{REFERENCES}

1. Hauben DJ. The history of hypospadias. Acta Chir Plast 1984; 26:196-199.

2.Murphy JP. Hypospadias. In: George W Holcomb,J. Patrick Murphy. Ashcrafts pediatric surgery. $5^{\text {th }}$ ed. Saunders 2010;60:775-790.

3.Stein R, Schroder A. Thuroff JW,. Surgical Atlas Primary hypospadias repair with buccal mucosa; BJU International. 2006, 97,871-889.

4. Laurence S Baskin. Hypospadias. In: Jay L Grosfeld, et al. Pediatric surgery. 6th ed. Mosby Elsevier 2006;119:1870-1898.

5. Ehrlich RM, Alter G. Split-thickness skin graft urethroplasty and tunica vaginalis flaps for failed hypospadias repairs. J Urol 1996; 155(1):131134.

6. Linda AB, Ranjiv I M, Steven GD. Radical bulbar dissection to correct server chordee in proximal hypospadias. J Urol. 2000; 164(4): 1347- 49 ,

7. Manzoni G, Bracka A, palminteri $E$ et al. Hypospadias surgery . When, what and by whom? B J Uint.2004; 94:188-95.

8. Barbagli G, Palminter E, Guazzoni G: one Stage and multi -stage penile urethroplasty in 60 adult patients after failed repair.J Urol.2005; 173(4): 89-91, 2005.

9. Andrich DE, Leach CJ, Dunglison N. The problems of penile and proximal hypospadias repair J Urol.2002; 167(4): 8486.

10. Sedberry- Ross S, Sitisser B, Hederson C.G et al. Split prepuce in situ onlay in hypospadias repair: 17 year of experience. J Urol.2007; 178:1663-67.

11. Dime J: The selective use of a single stage and a twostage technique for hypospadias correction in 157 consecutive cases with the aim of normal appearance and function. $\mathrm{Br} \mathrm{J}$ Plast Surg.1998; 51:195-201.

12. Lam PN, Green field SP, williot P. Two - stage repair in infancy for severe hypospadias with chordee, long - term results after puberty. J Urol.2005; 174(4): 1567-721.

13. Tolfer JR, Quaba BI,Peddi NC. An Investigation into the role of water proofing in a two-stage hypospadias repair $\mathrm{Br}$. J. Plast Surg. 1998; 51: $542-46$.

14. Sauvage P, Becmeur F, Geiss S, Fath C. Transverse mucosal preputial flap for repair of 
severe hypospadias and isolated chordee without hypospadias: a 350-case experience. J Pediatr Surg 1993; 28(3):435-438.

15. Borer JG, Bauer SB, Peters CA, et al. Tubularized incised plate urethroplasty: expanded use in primary and repeat surgery for hypospadias. J Urol. 2001; 165(2):581-585.

16. Sulaiman AA. Repair of hypospadias in AlKhansa'a Mosul pediatric surgery center (analysis of 125 cases). Annals of the college of medicine Mosul 2008; 34(2): 109-117.

17. Saafan HA. Two Stages repair of proximal hypospadias: Review of 33 cases. Annals of Pediatric Surgery. 2010 April; 6, (2), PP 89-92.

18. Singh N, Sharma E, Saraf R, Goswamy HL. Tubularized incised plate urethroplasty (Snodgross procedure) for distal penile hypospadias - a regional centre experience. Indian J Urol 2005; 21:109-11.

19. Ismail KA. Proximal Hypospadias: Is Still There a Place for Two Stage Urethroplasty?.Annals of Pediatric Surgery. 2009 October;5 (4), PP 274281.

20. Badawy H, Fahmy A. Single- vs. multi-stage repair of proximal hypospadias: The dilemma continues; Arab Journal of Urology. 2013;11,174-181.

21. Snodgrass WT and Lorenzo A: Tubularized incised plate urethroplasty for proximal hypospadias. BJU. 2002; 89:90-93.

22. Mamdouh A Aboulhassan, Khaled HK Bahaaeldin, Omar M Mansour and Ali M. Ziada. Comparative Study between the Tubularized Incised Plate Urethroplasty and Single Faced Onlay Preputial Island Flap in the Management of Mid-Penile Hypospadias, Annals of Pediatric Surgery. 2005 October ; 1, (1): PP 32-37.

23. Snodgrass $W$, Bush N. Tubularized incised plate proximal hypospadias repair. Continued evolution and extended applications. J Pediatr Urol. 2011; 7:2-9.

24. Sujijantararat $P, \quad$ Chaiyaprasithi $B$. Comparative outcome between transverse island flap onlay and tubularized incised plate for primary hypospadias repair. Asian J Surg. 2009; 32(4):229-33.

25. AlEkrashy M. A., Tarek Gobran, Ahmad Ezzat and Amin Saleh. Long_term outcoms after tubularized incised plate urethroplasty(TIP) for proximalhypospadias.Z.U.M.J.;2012March;18; (2).

26. Byars LT. A technique for consistently satisfactory repair of hypospadias. Surg Gynecol Obstet .1955;100: 184-90.

27. Gershbaum MD, Stock JA, Hanna MK. A case for 2-stage repair of perineoscrotal hypospadias with severe chordee. J Urol. 2002; 168:1727-8.
28. Arshad AR. Hypospadias repair: Byar's two stage operation revisited. Br J Plast Surg 2005; 58:461-6.

29. Cheng EY, Kropp BP, Pope 4th JC, Brock 3rd JW. Proximal division of the urethral plate in staged hypospadias repair. J Urol. 2003; 170:1580-3.

30. Aseem RS, Rakesh PP, Douglas AC. The 2stage hypospadias repair. Is it a misnomer? J Urol. 2004; 172:1714-6. 